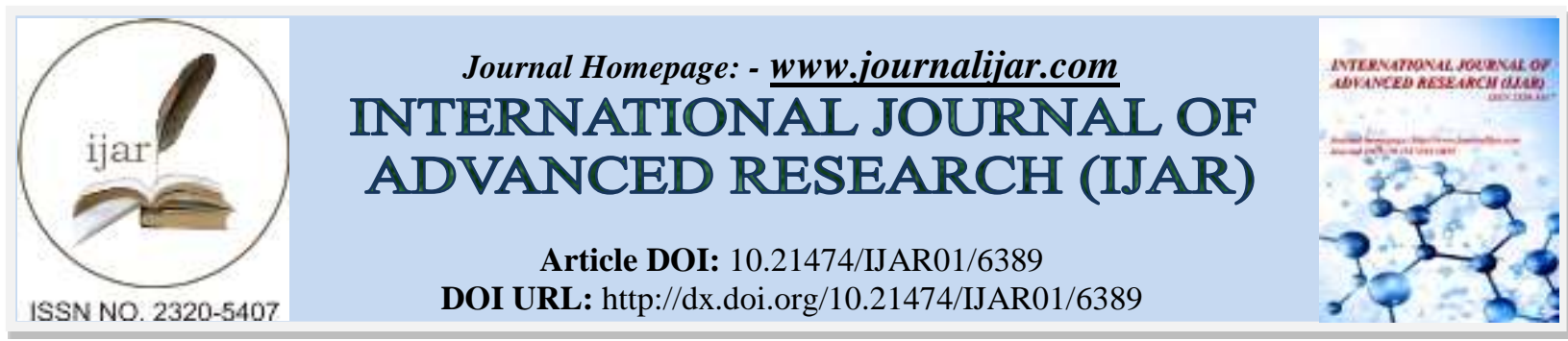

RESEARCH ARTICLE

\title{
A REVIEW ON CHALLENGES AND BARRIERS: IMPLEMENTATION OF THE EXISTING NURSING RESEARCH FINDINGS.
}

Dr. Gitumoni Konwar.

Ph. D., M.Sc. (Medical Surgical Nursing), PG Diploma (Hospital \& Health Management) Associate Professor, Regional College of Nursing, Guwahati-32, Assam, India.

\section{Manuscript Info}

Manuscript History

Received: 23 November 2017

Final Accepted: 25 December 2017

Published: January 2018

Key words:-

Challenges, Barriers, Implementation,

Existing research findings.

\section{Abstract}

The knowledge hub of all profession is based in the field of scientific enquiry. The Nursing research has an incredible influence on the professional growth of Nursing. The reflection of nursing profession is based on the improvement in the nursing practice. Successful implementation of the research findings or evidence is essential for enhancement of present and upcoming proficient nursing practice. Nurses are facing challenges while implementing these valuable research findings into practice. There are many barriers in implementation of the research findings. Implementation of existing research findings has the key to provide best quality and excellent nursing care. The objective of this review was to explore the challenges and barriers faced by the nursing fraternity while implementing the existing research findings in to practice.

Copy Right, IJAR, 2018,. All rights reserved.

\section{Introduction:-}

Today the word is changing very swiftly due to fast growing technology. The health care professions also progressing with advanced sophisticated technology. We must develop a sound base of professional nursing practice through implementation of existing research to meet the demand of the advancement of quality and excellence in health care. Nursing research worldwide is committed to rigorous scientific inquiry that provides a significant body of knowledge to advance nursing practice, shape health policy, and impact the health of people in all countries. Nurse researchers bring a holistic perspective to study individuals, families, and communities involving behavioral and translational approach. The priorities for nursing research reflect nursing's commitment to the promotion of optimal health and healthy lifestyles to enhance quality of life of the public. The successful implementation of existing research findings is the pivot of the nursing profession to enhance sound nursing education, practice and research. The primary goal of the nursing profession is to provide best nursing care to the society. But the implementation of the findings is crucial due to the presence of challenges and barriers in the field of nursing practice. The challenges and barriers must be eliminated for implementation of the existing research findings to meet the demand of the nursing arena. The present review aims to highlight the challenges and barriers to be overcome while implementing the existing research findings. The critical path should be delineated for enhancement of the care provided by the nurses in every setting.

\section{Research Implementation:-}

Research dissemination and implementation are essential components for betterment of nursing practice. If research findings are not implemented, the conduct of research becomes a wasted effort. Nurse researchers need to exert as 
much effort in implementing research findings as they do in conducting research in the first place. In the past, many actions of nurses have been based on tradition or authority. This is no longer acceptable in modern society; evidence-based practice must be addressed to make a significant transformation in nursing practice. Nurses should be able to justify the decisions they make and the care they give. Many nursing leaders have indicated the high priority that should be placed on the implementation of research findings in nursing practice.

\section{The Challenges in implementation of existing research findings:-}

In twenty-first century, implementation of research findings in practice has been considered vital to nursing profession. To improve clinical cost-effectiveness and outcomes, professional associations and educators have required nurses to build their practice on research findings. However, despite the increasing quantity and improving quality of nursing researches, incorporating research results into clinical practice remains a significant challenge (Thompson C, et al., 2005; Estabrooks, et al., 2003).

Nurses face a real challenge when translating best evidence into clinical practice. For example, the relevant research-based databases are not comprehensive in many areas. Also, there is an ongoing explosion in the amount and type of information available. A need also exists for accurate and systematic ways to make inferences from the research as applied to particular patient populations. Getting research into practice is not as simple as choosing an intervention and hoping for the best. Aside from the intervention itself, mediating factors include the characteristics of the patient and the practitioner and the desired behaviour change. Furthermore, administrative or financial policies may exist within organizations and settings that act as disincentives to improving the practice of individuals (Fink, et al., 2005; McCleary and Brown, 2003). Policies can be changed to reflect current guidelines (developed from the evidence) in nursing practice. For example, the traditional method for verifying the placement of a nasogastric tube was air insufflations. However, according to current nursing research, the accurate method for verifying placement is radiologic examination (Metheny and Titler, 2001).

Winch, et al., (2005) discusses a process for fitting research evidence into practice that overcomes well-known barriers in order to influence clinical decision-making and practice change. Read, Think, Do! is a problem-solving approach to research utilization and practice development. This method acknowledges the complexity of problemsolving processes from the outset by looking for the evidence, assessing the value to practice, and addressing the social and cultural milieu of the practice setting to ascertain the best strategies for initiating and sustaining practice change. This approach draws distal forms of empirical knowledge that have the capacity to improve patient outcomes into the proximal knowledge base of the clinical nurse. This is achieved by collaboration, planning and evaluation involving all levels of staff and a specialist facilitator, the Clinical Nurse Consultant in evidence-based practice.

Many nurse leaders have pointed out the continued gap between nursing researches and nursing practice. Barriers to the implementation of nursing research have been identified in various studies. Six common barriers to implementation of nursing research findings are a) Nurses' Knowledge \& Attitude on research, b) Dissemination of Research Findings, c) Institutional Support for Research, d) Replication of the Research Findings, e) Nurse researchers are not nurse clinician, f) Nurse clinicians are not nurse researcher

\section{The Barriers in implementation of existing research findings:- Nurses' Knowledge \& Attitude on research:-}

A great deal of evidence indicates that nurses are unaware of many research findings. Funk, et al., (1991) reported that nurses' lack of awareness of research was listed by $77.2 \%$ of the administrator respondents as the greatest barrier to research utilization. The study of Canadian nurses conducted by Paramonczyk's established that lack of awareness of research findings was listed as the second highest barrier. Some research indicates that nurses may have knowledge about research but they are reluctant to change their traditional practices. So even today, nurses indicate that their lack of knowledge of research findings is a serious barrier to research utilization (Paramonczyk, 2005). In addition, the support of administrators was also important in determining research use. Nurses with positive attitudes were more likely to use research findings.

Champion and Leach (1989) found that nurses' attitudes toward research were positively related to research utilization $(r+.55)$. Nurses with positive attitudes were more likely to use research findings. Attitude was more strongly correlated with research utilization than the other two variables that were considered: institutional support and availability of research findings. These strategies to help nurses to develop positive attitude towards research 
including role model in the clinical area, research course at the undergraduate level that help the student to develop enthusiasm early in their careers.

\section{Dissemination of Research Findings:-}

Inadequate dissemination of nursing research findings involves two areas. Most nursing research studies are never published or presented in the research workshops/conferences. On the other hand published or presented study findings were higher than the level of understanding of practicing nurse. Research should be reported in the journals that are read most frequently by clinicians and that these reports be more readable and contain clinical implications (Funk, et al.,1991). Nurses need to make an effort to publish in the popular clinical journals. It appears that we have made very little progress in communicating the results of nursing research to nurses, much less to the general public! (Brooten, et al., 1999; Kennedy, 2004).

\section{Institutional Support for Research:-}

Nurses frequently perceive that there is little institutional support for nursing research. A study conducted by Wang, et al., on "Barriers to and facilitators of research utilization in China found that the lack of authority was ranked as the greatest barrier (15.7\%), followed by the lack of time (13.4\%) \%) and language barrier (15.0\%). Poor institutional support has been identified as a barrier to research implementation in all of the published studies. The researcher reported that the nurses do not have "enough authority to change patient care procedures" and "insufficient time on the job to implement new ideas" Funk, et al., 1995.

The facilitating factors that overcoming barriers of research utilization was $80.0 \% \& 64.2 \%$ of academic staff and practical nurses respectively reported that; given adequate training in research utilization was extremely important. Practical nurses are facing many difficulties in implementing research utilization. Facilitating factors that overcome barriers was reported as; given adequate education in Research and its utilization \& the support from nursing manager (Magda, et al., 2016).Time constraints are inherent in clinical practice, and they are exacerbated by increasing demands for nursing care. The nursing fraternity must believe the environment is conducive for the use of research.

\section{Replication of the Research Findings:-}

Replication of research is essential for "building and continued development of the scientific basis of any discipline. The research to be ready for use in practice, the findings must have been replicated and demonstrated to be true with real patients as well as with healthy subjects. There are a few studies on nursing practice problems, but some of these studies contain serious threats to validity, which makes the use of findings is questionable. Often research is carried out with healthy subjects rather than the hospitalized patients. The findings may be quite different between the two types of subjects. Replication can be used to overcome design limitations, increase validity of findings, and bring about correction of error. In addition, potential barriers and solutions to increase replication were identified. Replication is a critical step in validating research to build evidence and to promote use of findings in practice (Fahs, et al., 2003). Hence study findings should be implemented if the study has been replicated in several clinical settings, with similar results being found.

\section{Nurse researchers are not nurse clinician:-}

The nurses who have been conducting research are not involved in the nursing practice. The uptake of research evidence into nursing practice is also influenced by the nature of the evidence itself, including its availability, simplicity, clarity, and perceived relevance (Hutchinson and Johnston, 2006). Most results from research appear first in peer reviewed journals, but the small numbers of clinically important studies are spread thinly through a vast number of publications; readers are bound to be overwhelmed (Haynes and Haines, 1998). Also the study conducted by Magda, et al., (2016) revealed that, $60 \%$ of practical nurses does not use research findings in patient care/patient care procedures. Enhance research skills of practical nurses, enhance support from nursing manager and initiate a link between health institutions and academic researchers for adoption of research finding. The terminologies used by the nurse researcher while disseminating the research findings are complicated in nature. Practitioners have difficulty in finding, assessing, interpreting, and applying current best evidence.

\section{Nurse clinicians are not nurse researcher:-}

It is heart breaking that the practicing nurses were not involved in conducting the research studies. Greatest barriers to research utilization reported included lack of awareness of available research literature, inadequate skills in critical appraisal and lack of support for implementation of research findings (Hutchinson, and Johnston, 2004). The 
practicing clinicians have received little or no training in the use of tools that would help them find evidence on which to base their practice (Pravikoff, et al., 2005). The healthcare system does not provide the incentive for nurses to engage in research or to avail themselves of research findings (Mehrdad, et al., 2008). The clinical practice can be progressed by improvement of communication between academic and clinical practice environments. Moreover the availability of more relevant research and colleague support is an opportunity to implement existing research.

\section{Conclusion:-}

It is essential to develop insight among the nurses about implementation of existing research findings into practice to develop their standards of nursing care provided. Nurses in every healthcare organization should use research findings to assess their skills, develop and implement policies and procedures. Thus effective clinical interventions can be performed to provide quality nursing care to the individual, family and community. Application of research based nursing care service will enhance positive outcomes for patients. A range of interventions has been developed to increase the implementation of research into health policy and practice. In particular, clinical guidelines, audit and feedback, continuing professional education and financial incentives are widely used and have been extensively evaluated. To maximize the benefits of nursing research and the delivery of high quality care, it is important to develop a project that enhance the process of identifying the barriers in developing, conducting, disseminating and implementing nursing research. Then we can identify the barriers and determine the Challenges for Implementation of the existing nursing research findings for excellent nursing practice.

\section{References:-}

1. Thomas A. Identifying barriers to research dissemination in a developing country: a follow-up study. https://stti.confex.com/stti/congrs13/webprogram/Paper53368.html

2. American Nurses Association Position Statement: Education for Participation in Nursing Research. Available: http://www.nursingworld.org/readroom/position/research/rseducat.

3. Thompson, C., McCaughan, D., Cullum, N. and Sheldon T. (2005): Barriers to evidenced-based practice in primary care nursing- why viewing decision-making as context is helpful? J Adv Nurs., 52:432-44.

4. Estabrooks, C.A., Floyd, J.A., Scott-Findlay, S., O'Leary, K.A. and Gushta, M. (2003): Individual determinants of research utilization: a systematic review. J Adv Nurs., 43:506-20.

5. Pipe, T. B., Wellik, K.E., Buchda, V. L., Hansen, C. M. and Martyn, D. R. (2005): Implementing EvidenceBased Nursing Practice. Urol Nurs., 25:365-70.

6. Fink, R., Thompson, C.J. and Bonnes, D. (2005): Overcoming barriers and promoting the use of research in practice. J Nurs Adm., 35:121-9. http://www.ncbi.nlm.nih.gov/pubmed/15761309

7. McCleary, L. and Brown, G.T. (2003): Association between nurses' education about research and their research use. Nurse Educ Today., 23:556-65.

8. Metheny, N.A. and Titler, M.G. (2001): Assessing placement of feeding tubes. Am J Nurs. 2001;101:36-45

9. Winch, S., Henderson, A. and Creedy, D. (2005): Read, Think, Do!: a method for fitting research evidence into practice. J Adv Nurs., 50:20-6.

10. Funk, S.G., Champagne, M.T., Wiese, R.A. and Tornquist, E.M. (1991): Barriers to Using Research Findings in Practice: The Clinician's Perspective. Applied Nurs Res., 4:90-5

11. Paramonczyk, A. (2005): Barriers to implementing research in clinical practice. Can Nurse., 10:12-5. http://www.ncbi.nlm.nih.gov/pubmed/?term=Paramonczyk\%2C+2005

12. Champion, V.L. and Leach, A. (1989): Variables related to research utilization in nursing: an empirical investigation. J Adv Nurs., 14:705-10.

13. Brooten, D., Youngblut, J.M., Roberts, B.L., Montgomery, K., Standing, T., Hemstrom, M, et al. (1999): Disseminating our breakthroughs: enacting a strategic framework. Nurs Outlook., 47:133-7.

14. Kennedy, C. (2004): A typology of knowledge for district nursing assessment practice. J of Adv Nurs., 45:4019.

15. Wang, L.P., Jiang, X.L., Wang, L., Wang, G.R. and Bai, Y.J. (2013): Barriers to and Facilitators of Research Utilization: A Survey of Registered Nurses in China. PLoS ONE, 8(11):e81908. https://doi.org/10.1371/journal.pone.0081908

16. Funk, S.G., Tornquist, E.M. and Champagne, M.T. (1995): Barriers and facilitators of research utilization. An integrative review. Nurs Clin North Am., 30(3):395-407.

17. Mohsen, M.M., Safaan, N.A. and Okby, O. A Clinical Study facilitating Factors for Overcoming Barriers Facing Nurses for Research Utilization in Clinical Settings. Am J Nurs Research. 2016;4:13-24

18. Fahs, P.S., Morgan, L.L. and Kalman, M. (2003): A call for replication. J Nurs Scholarsh., 35:67-72. 
19. Hutchinson, A.M. and Johnston, L. (2006): Beyond the BARRIERS Scale: commonly reported barriers to research use. J Nurs Adm., 36:189-99.

20. Haynes, B. and Haines, A. (1998): Barriers and bridges to evidence based clinical practice. BMJ., 317:273-76

21. Hutchinson, A.M. and Johnston, L. (2004): Bridging the divide: a survey of nurses' opinions regarding barriers to, and facilitators of research utilization in the practice setting. J Clinical Nurs.,13:304-15

22. Pravikoff, D.S., Tanner, A. B. and Pierce, S.T. (2005): Readiness of U.S. Nurses for Evidence-Based Practice. Am J of Nurs., 105(9):40-51

23. Mehrdad, N., Salsali, M. and Kazemnejad, A. (2008): The spectrum of barriers to and facilitators of research utilization in Iranian nursing. J Clinical Nurs.,17:2194-2202 